\title{
The Challenges Facing the Implementation of Agency Banking In Kenya a Case Study of Kcb Limited Mombasa County
}

\author{
Titus Odhiambo Agalla \\ Research Project Submitted To The School Of Human Resources And Development, In Partial Fulfillment Of \\ The Requirement For The Award Of A Masters Degree In Business Administration At Jomo Kenyatta University \\ Of Agriculture And Technology
}

\begin{abstract}
The Central bank of Kenya continues to support innovations that will broaden the financial inclusion of the majority of the Kenyans. The financial access survey of 2009 shows that $32 \%$ of Kenya's bankable population remains totally out of the orbit of financial services and many more being served by the informal financial system (CBK 2009). The Central bank took extensive reviews of the agent banking. A study by Bankable associate Frontier International Consultancy Firm was commissioned to review practices in Latin America, Asia and Africa on agent banking. To get more insight, a team from Central Bank (CBK), Ministry of Finance and Kenya Bankers Association (KBA) undertook a study tour on agent banking in Brazil and Colombia (CBK website 2010). After the ground work, Kenya Government through Central Bank of Kenya (CBK) unveiled the agent banking guidelines (GUIDELINES ON AGENT BANKINGCBKJPGI15) to ensure safe, efficient and inclusive financial system as envisaged by vision 2030.("Professor Ndungu's speech on 14 January 2010') The study sought to establish whether the risks associated with agency banking, Policies, procedures governing Agency banking, technological, operations and awareness as hindrances to the implementation of agency banking within Mombasa Business District a case study of Kenya Commercial Bank. The study used

descriptive also known as survey design in which the target population was branch manager's agent banking mangers and agent banking consultants in selected Kenya commercial bank. Data was collected through a questionnaire with open and closed ended questions. Data was analyzed using descriptive statistic Microsoft excel tools and data presented by use of both quantitative and qualitative analysis in the form of frequency tables, pie charts, bar charts and percentages.
\end{abstract}

\subsection{Background of the Study}

\section{Introduction}

The agency banking model is one in which banks provide financial services through nonbank agents, such as grocery stores, retail outlets, post offices, pharmacies, or lottery outlets. Agency banking was introduced during the 2009 budget and was enshrined in the Finance bill of 2009. Agency banking takes customers out of the bank halls to kiosks and villages. Investors have pumped billions into new platforms that offer agency banking services Mulupi (2011). This model allows banks to expand services into areas where they do not have sufficient incentive or capacity to establish a formal branch, which is particularly true in rural and poor areas where as a result a high percentage of people are unbanked. Agency banking is quickly becoming recognized as a viable strategy in many countries for extending formal financial services into poor and rural areas in that agency banking enables clients to store, send and receive electronic money through local agents, rather than travelling to the nearest bank branch.

In recent years, agency banking has been adopted and implemented with varying degrees of success by a number of developing countries, particularly in Latin America. Brazil is often recognized as a global pioneer in this area since it was an early adopter of the model and over the years has developed a mature network of agency banks covering more than $99 \%$ of the country's municipalities. Other countries in Latin America have followed suit, including Mexico (2009), Peru (2005), Colombia (2006), Ecuador (2008), Venezuela (2009), Argentina (2010), and Bolivia (2006). Other countries around the world have also utilized the agency banking model to expand financial services, including Pakistan, Philippines, Kenya, South Africa, Uganda, and India.

The regulation, design, and implementation of agency banking vary across countries. These differences are evident in the variety of services offered by agents, the types of businesses acting as agents, the types of financial institutions that work through agents and the business structures employed to manage them.

Agency banking minimizes fixed cost; by leveraging existing retail outlets and stores hence financial service providers do not need to invest in their own physical infrastructure and also by using mobile phones rather than POS terminals as technology platform, financial service providers do not even have to incur equipment costs, for each new retail outlet opened. Such a variable cost structure makes the agent's economics very simple Plok,( 2009). 


\subsubsection{Kenya Commercial Bank Profile}

The history of Kenya Commercial Bank (KCB) dates back to 1896 when its predecessor, the National Bank of India opened an outlet in Mombasa. Eight years later in 1904, the Bank extended its operations to Nairobi, which had become the Headquarters of the expanding railway line to Uganda. The next major change in the Bank's history came in 1958. Grindlays Bank merged with the National Bank of India to form the National and Grindlays Bank. Upon independence the Government of Kenya acquired $60 \%$ shareholding in National \& Grindlays Bank in an effort to bring banking closer to the majority of Kenyans. In 1970, the Government acquired $100 \%$ of the shares to take full control of the largest commercial bank in Kenya. National and Grindlays Bank was renamed Kenya Commercial Bank. According to the Chief Executive Officer of KCB, the main aim of introducing the KCB Mtaani banking agency was to make the bank more accessible to the target market and to complement the other existing channels. By April 2011, KCB had a total of 500 agents in operation and the number was bound to increase to 2000 by the end of the same year (KCB, 2011).

\subsubsection{KCB 'Mtaani' Agency banking}

The KCB agency banking proposition was launched on 14 April 2011 setting the pace for the provision of formal banking services at the grassroots. It was aptly named KCB Mtaani', a development the bank hopes will assist in reaching over 9 million unbanked Kenyans who have the capacity to engage in profitable banking relationships but do not have access to the formal banking infrastructure. The bank initially began with a pilot phase with 30 agents for two months that recorded over 200 successful transactions and had plans to roll out services to 2000 agents countrywide by the end of year 2011. The bank has a target of attaining 5,000 operating agents spread across Kenya in a number of years. The main purpose is to give customers easy accessibility to banking services. KCB Mtaani is a cost-effective way for the bank to expand its reach without the necessity to invest in brick and mortar and will allow the bank to leverage on its technology platform to provide innovative banking products and services to all. At the initial stage the agents were connected to the KCB agency banking platform through the KCB Connect and equipped with a telephone set to facilitate deposit taking and withdrawals. For this to happen agents need to open and fund an agency float account, which is a non-interest bearing account, with KES100, 000. customers must also be registered with KCB Connect to be able to transact at agency outlets. KCB's long term vision is to link its agents with its core banking system through the internet banking proposition, point of sale terminals and predictive dynamic quoting PDQ machines to enable them undertake such services as balance enquiries, loan repayments and requests for cheque books and account statements. In a bid to increase the number of agents, KCB partnered with Post Office Corporation (PCK) to offer agency banking services to KCB customers (KCB, 2011).

\subsection{Statement of the Problem}

The World Bank estimates that in many countries, over half of the population, "the unbanked", has never had a bank account. The poor tend to be terrified of banks, since they are often humiliated or ignored when they try to enter them. That means they cannot leave their savings anywhere safe, pay a bill without walking with the cash to the office or prove that they are credit worthy, Martin Garner (Wireless Intelligence, 2007).

Studies done by CGAP in other countries, specifically in Brazil, Peru and Chile has shown that there is growing interest in many parts of the developing world in delivering financial services through the retail agents, including post offices, airtime sellers and local shops. Many potential advantages have also been indentified in those countries for providers of banking services being able to transact local retail agents. (Ignacio and Siedek, 2008).

This study seeks to determine the challenges of implementing agency banking in Kenya Commercial Bank Mombasa County. Other studies have been done in the areas of adoption and alternative banking channels. They include, Nyakondo (2010), did a survey on factors influencing banking industry to adopt strategic positioning in mobile banking. The study found that banks had adopted moderate technology to a moderate extent and there was need to do more in this area; Ngigi (2010), conducted a study on challenges of E-banking adoption which revealed that e-banking was a relatively new distribution channel in Kenya and the key challenges facing it included ICT security, quality as well as consumer awareness program me. Otieno (2006) investigated the internet banking technology adoption among commercial banks in Kenya.

Ontunya (2006) on the other hand did a survey of consumer adoption of mobile phone banking in Kenya. Mugambi (2006) in her survey of internal delivery systems in KCB observed that the bank should address various challenges facing it so as to improve on quality of service. In her study of "the role of executive development in corporate strategy implementation, a comparative study of KCB and National Bank of Kenya," Njuguna (2007) observed that both banks realize that well equipped executive confer competitive advantage to their companies. Kiptugen, (2003) observed that KCB has addressed its changing competitive situation by formulating and implementing strategic responses that include restructuring, marketing, information technology 
and culture change. However there still was need for more strategic actions that need to be undertaken by KCB in order to enable the bank to fully match the environment in which it operates.

Although a number of studies have been done on banking sector in Kenya, a knowledge gap still exists on the challenges facing the implementation of agency banking in Commercial banks in Kenya. It is in the background of these issues that this research study seeks to fill in the gap by answering the question; what are the challenges of implementing agency banking in KCB in Mombasa County given the changing and turbulent environment it is operating in.

\subsection{Research Objectives}

\subsubsection{General Objective}

The main objective of the study was to establish the challenges facing the implementation of Agency Banking in Kenya.

\subsubsection{Specific objectives}

The Specific objectives include the following:

1. To establish how technological risks affects the implementation of agency banking.

2. To establish how operational structure affects implementation of agency banking.

3. To establish how regulation of agency related laws affect the implementation of agency banking.

4. To determine how lack of training affects the implementation of agency banking.

\subsection{Research Questions}

This study was guided by a number of questions aimed at bringing out the pertinent information to the study in line with is specific objectives. The study sought to answer the following questions;

1. How the operational structure of agency banking does affect the implementation of agency banking?

2. How does regulation of agency related laws affect the implementation of agency banking?

3. What are the effects of Technological factors on the implementation of agency banking?

4. How lack of training hinders implementation of agency banking?

\subsection{Justification of the study}

The findings of this study will go a long way in assisting Commercial Banks formulate or design appropriate mechanisms to identify and overcome challenges while implementing its agency banking strategy so as to achieve the set organization's goals and objectives. The findings will also help other similar organizations to identify and tackle the challenges encountered in agency banking implementation process.

The study is expected to contribute to the existing literature in the field of challenges facing the implementation of agency banking strategy. It is hoped that the study will form the basis for further research on this subject.

The study will be valuable to the policy makers in addressing issues related to agency banking and its implementation in regards to financial institutions and other relevant institutions.

\subsection{Scope of the study}

A sample population of $39 \mathrm{KCB}$ staff (Head of departments and agency banking managers) in Mombasa County will be investigated. The target correspondents would be Head of Departments of Agency banking and Agency banking managers.

\subsection{Limitations of the study}

One of the major limitations faced by the researcher is the time frame. Agency banking having been launched in Kenya in May 2010 is a fairly new model within the within banking sector. Hence this research would only cover a period between the years 2010 and 2013. The period to be covered by this research would generally be short since most of the agency banking department within the sampled commercial bank are in their formative stages, thus a more comprehensive view of the topic under study may not be attained.

\subsection{Introduction}

\section{Literature Review}

This chapter presents a review of the related works on the subject under study presented by various researchers, scholars, analysts and authors. The review has covered the various researchers' issues on the factors affecting agency banking roll out in Kenya. The materials are drawn from several sources which are closely related to the theme and the objectives of the study. The review is done from a general perspective owing to the limited availability of literature that has focused directly on challenges of agency banking implementation. 


\subsection{Review of Theoretical Literature \\ 2.2.1Theory of Financial Inclusion:}

Financial inclusion is the core of the Central Bank of Kenya's reform agenda to support Kenya's development blue print, vision 2030. Financial inclusion is defined as the process of ensuring access to financial services and timely and adequate credit where needed by vulnerable groups such as weaker sections and low income groups at affordable costs. (Rangarajan's committee) Financial inclusion is defined as "the policy goal of reaching all financially excluded households with a full range of responsibly delivered, affordably priced and reasonably convenient formal financial services." (Chriten, 2011) Evidence shows that financial inclusion is key to reducing the economic vulnerability of households, promoting economic growth, alleviating poverty and improving the quality of peoples' lives. Financial inclusion is a process that ensures ease of access and ability to use formal financial system by all members of an economy. Due to the high connectedness between financial and social exclusion, an inclusive financial system have been identified to transcend individual gains to enhance societal benefits. It's attributes of enhancing appropriate financial decision-making and capability of financial users are expected to complement the investment redistribution role of financial service providers. Thus, an all inclusive financial system enhances efficiency and welfare by establishing a 'functional' equilibrium between the financial and real sectors of an economy. In a wider context, financial inclusion contributes to economic growth through value creation of small entrepreneurship and businesses, positive spillovers, improvements in human development indicators (health, nutrition, and education), reduction in inequality and poverty (Chriten, 2011).

The key theories of financial inclusion include:

\subsubsection{Business Correspondent/Business Facilitator Model (BC/BF)}

$\mathrm{BC} / \mathrm{BF}$ model practiced by banks is a relatively new concept that has successfully been practiced in India. Banks increase their reach by engaging local 'correspondents' and 'facilitators' to offer their services. Facilitators are individuals while correspondents may be individuals or institutions. They help the bank reach more people in areas where bank branches do not exist or by easing traffic at existing branches. This channel is also meant to distribute product information. But these advantages come with costs. Banks have to realize that, for the model to succeed, the BC's /BF's have to be compensated adequately so that they too see this as a business opportunity. Further, client fears and misconception about these four channels should be addressed. Banks will have to increase trust, provide enough incentives and use technology for adequate reporting. A policy oriented approach can be to let the corporate houses and non-banking financial companies which want banking licenses instead. Thus banks can continue to be responsible for KYC/AML and other norms to cover the risks to the system and BCs will have balance sheets large enough to plan sufficiently large technological investments.

\subsubsection{Agency Theory}

Economists have generally used a far more inclusive definition of agency relationships than does the law. For example, Stephen Ross defined agency relationships as arising "between two (or more) parties when one, designated as the agent, acts for, on behalf of, or as representative for the other, designated the principal in a particular domain of decision problems." Stephen A. Ross, The Economic Theory of Agency: The Principal's Problem, 63 AM. ECON. REV. 134, 134 (1973).

The complexity of agency relationships has created a fertile field for legal and economic analysis. Both a principal and an agency form an agency relationship because they each expect to receive some net benefit. The parties expect that the relationship will lead to an efficient division of labor. Thus, a principal might benefit from the greater expertise of an agent, such as where shareholders of a corporation hire managers to skillfully oversee their ownership interest in the firm. Similarly, agency relationships allow investment in many different productive enterprises allowing those with wealth to diversify their holdings, insulating them from unforeseeable risks inherent in any one given venture. Sometimes principals seek agents where the principal recognizes, ex ante, the potential for some non-welfare maximizing behavior, such as when a parent creates a spendthrift trust for a child. Even where a principal has greater capabilities with respect to a task than an agent, the principal may also have higher opportunity costs, and thus capture a Pareto gain from the agents' relatively inexpensive labor.

Despite these obvious advantages, agency relationships also come with significant costs. One of the central insights of economic agency cost theory over the past generation is that while an agency relationship may be relatively efficient in comparison to no relationship at all, the incentives of a principal and her agency nevertheless are frequently (if not always) misaligned. Principals virtually never enjoy representation of an agency with the same cost-to-benefit ratio for expending resources on the completion of a given productive task. For example, in the classic corporate context, the manager of a company who has no wealth invested in the corporation she manages will have relatively little incentive to carefully manage corporate funds in comparison 
to the shareholders of that corporation. Similarly, because a real estate agency receives only a percentage of the purchase price of a home, he has less incentive to invest time driving up the marginal sale price than the actual seller the agency represented. Social norms, business practices, contract terms, and the legal system often attempt to more closely align the incentives of agents and their principals. When a stranger at the beach asks another to watch his belongings, most people will invest some care and attention for those belongings even at a cost to themselves. Shareholders expect CEOs and other corporate managers to carefully and transparently document the expenditure of corporate resources to facilitate oversight. A real estate broker contract which provides a bonus for obtaining a large sale price might mitigate some of the agent's incentive to shirk his duties. And, the law holds a trustee liable to his beneficiaries for losses sustained from reckless or unauthorized investments.Indeed, so entrenched is the notion of the need to keep the incentives of agents and principals aligned that the law frequently holds principals liable for the misdeeds of an agent.

\subsection{Conceptual framework}

According to Mugenda et al (2003), a conceptual framework helps the reader to quickly see the proposed relationships between the variables in the study and show the same graphically. In this study the operational structure, Technological factors, regulation of agency related laws and lack of training are the independent variables while implementation of agency banking is the dependent variable.

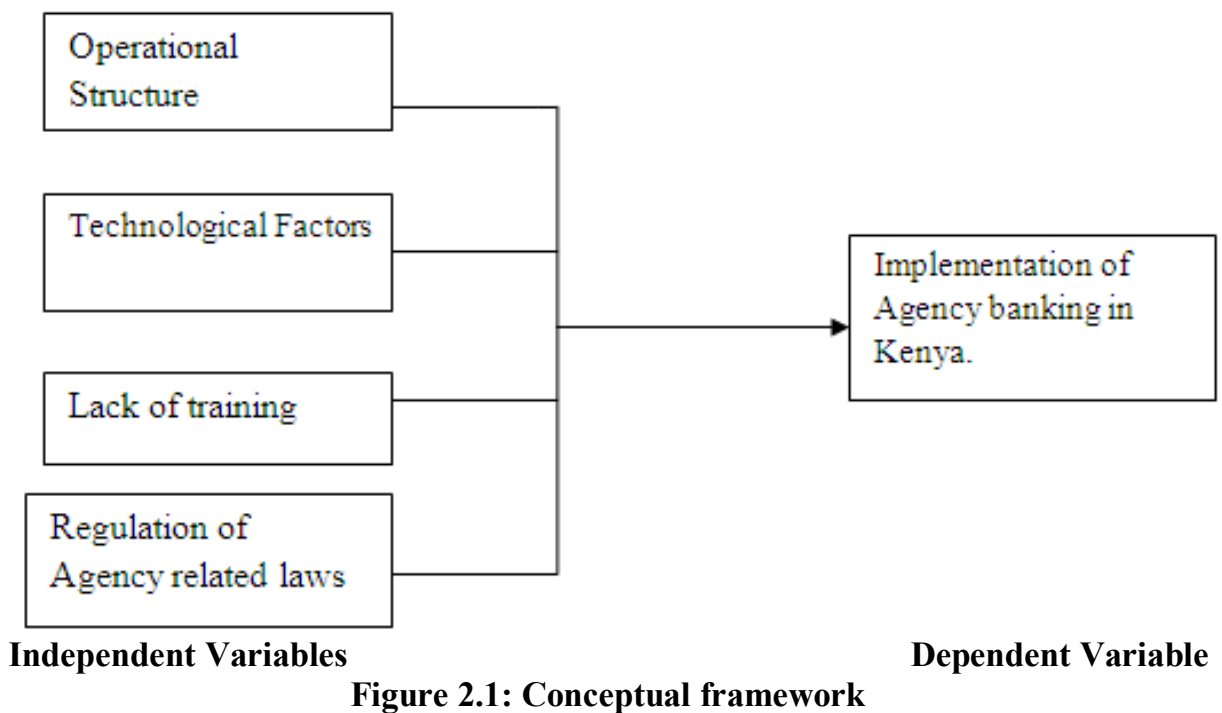

\subsection{1: Operational Structure}

Strategy used by an organization is fundamentally influenced by the operational structure of the organization. It dictates how policies and objectives are established and how resources are allocated. When an organization changes its strategy, the existing organization structure may be ineffective. Though an effective structure, organization's members are able to develop synergies that promote effective strategy implementation. Successful strategy implementation involves empowering others to do all the things needed to put the strategy into place and execute it proficiently (Thompson, Strickland and Gamble, 2007). Since the strategy implementation process imparts every part of the organization, every manager has to take an active role as a strategy implementer.

The most important outcome that leaders, managers and planners should aim from successful strategy implementation is real value added through goal achievement and increased stakeholder satisfaction. Successful strategy implementation in organizations depends on various factors. Aosa (1992) observed that strategy implementation is likely to be successful where there is a fit between several organizational elements. These elements include organizational structure, culture, resource allocation, systems and leadership.

The culture of an organization defines the social context in which an organization functions. It provides guidance to the organizational members in decision making, time management and energy investment, what kind of people to work for the organization and any other social activity done in the organization. Pearce and Robinson, (2003) states that culture affects the way managers behave in an organization including the decisions they make that affect the relationship between the organization, its strategy and the environment. Appropriate culture will facilitate successful strategy implementation.

According to Pearce and Robinson (2003), leadership ensures that organizational effort is united and directed towards achieving its goals and objectives. This makes leadership a very fundamental aspect in 
effective strategy implementation. Leadership provides the organization with vision, initiative, motivation and inspiration that affect the performance of the organization.

Organizational systems play a fundamental role in the strategy implementation effort and process. Systems means all procedures, formal and informal, that make the organization carry out its function on a daily basis and these may include capital budgeting systems, training systems, cost accounting procedures and budgeting systems. Poor information sharing, unclear responsibility and accountability mechanisms can lead to failure of strategy implementation.

Challenges that occur during the strategy implementation process are an important area of research because even the best strategies would be ineffective if not implemented successfully. It is the management's responsibility to ensure that the strategy is well understood organization wide before the implementation process begins. Clear understanding of a strategy gives purpose to the activities of each employee and allows them to link whatever task is at hand to the overall organizational direction (Byars et al, 1996). Lack of understanding of strategy is one of the obstacles to strategy implementation process.

Another very fundamental challenge is the ability of most organizations to maintain continuity in senior management. Senior managers might leave too soon after the implementation process has been started. When this happens, staff's commitment and enthusiasm for strategy implementation is undermined and they start to distrust the new strategy and prefer old and familiar situation. Staff attitudes and perspectives go a long way towards subverting the firm's plan.

Finding and bringing on board the right people to implement and manage change is a significant challenge to the strategy management process in many organizations today. Changes do not implement themselves. It is people that make them happen. Selecting people for key positions by putting a strong management team with the right personnel chemistry and mix of skills is one of the important steps towards successful strategy implementation (Thompson and Strickland, 1998).

\subsubsection{Technological factors}

Technology is the technical means people use to improve their surroundings. It is also knowledge of using tools and machines to do tasks efficiently. We use technology to control the world in which we live. Technology involves people using knowledge, tools, and systems to make their lives easier and better. Technology involves application of knowledge, tools and skills to solve problems and extend human capacity (Mberia, 2009). This means that technology is invented to make work easier and more effective. Any device invented and given the name technology means it makes work easier and more easily accomplished. Technology can be ancient technology or modem technology. Agency banking is a modem technology which uses recently invented gadgets such as mobile phones to operate.

Branchless banking (aka mobile banking) requires the outsourcing of cash transfers to these distributed networks of agents such as small shops. Technology application requires knowledge on card readers, mobile phones, barcode scanners, and sometimes personal computers that connect with the bank's server using a dial-up or other data connection as well as software requirements, inter-operability and protocols accepted. This determines the viability of the service by the agent. Technology involves people using knowledge, tools, and systems to make their lives easier and better. Technological factor in this study will be used to relate to mobile devices; software requires, inter-operability and protocols accepted and communications infrastructure (optimization and efficiency of bandwidth, communications interface, interference from other communications technologies).

Most mobile phones have an embedded chip that can be used to store value or provide secure authorization and identification that does not rely on a card reader, PC and modem combination or a POS terminal. However, are consumers' ready to embrace this new method of payment? What technological barriers affect the operation of agency banking agents? And are the consumers willing to embrace the new technology in the market? (Mberia, 2009)

\subsection{3: Lack of training}

These are perceived risks due to lack of understanding the business benefits to the bank and the economy at large. These refers to social issues, such as acceptability of mobile device and cultural fit of wireless application, as primary consideration for the wireless market and perceived usefulness of a wireless application all affecting behavior intention

(Mberia 2009) Understanding credit, operational and compliance risks are the major worries hindering implementation of Agency banking by commercial banks. Management of agency banking business requires man power and technological resources. Management of retail sized agents is a big challenge due to the risks mentioned above replicated in each agent. 


\subsection{4: Regulation of Agency related laws}

Agents play a critical role in acquiring new customers, enabling them to transact, and keeping them satisfied. They verify the identity of customers, both when clients sign up and at subsequent transactions.

The Policy makers and regulators have been facing problems to reconcile safe development of branchless banking and operation with increased levels of financial access (For broad branchless banking experiences). Central Bank of Kenya and Kenya Bankers Association are the promoters of Agency Banking. Central Bank issued the first Agency Banking prudential guide lines (CBKIPGI15 under section 33(4) of the Central Bank Act, (Central BANK WEBSITE) in 2011. CBK needed to address the development of the Agency banking model, the legal and regulatory framework, the model of agency banking and the branching regulations in the guidelines. In addition to vetting of the Agents by Central bank, a contract agreement is signed between the Commercial banks and Agency on responsibilities of each party. The guideline is issued under section 33(4) of the Banking Act which empowers CBK to issue guidelines to financial institutions. The Agency banking guidelines outlines the following:

The activities which can be carried out by an Agent; Serve as a set of minimum standards for data and network security, customer protection and risk management. Spells out responsibilities of the BODs of financial institutions (i.e. ensure they have oversight over Agency Banking standards); Approval of application for agency banking business by CBK Settlement of transactions - All transactions involving deposit, withdrawal payment and transfer from or to an account should be real time. Technology - Automatically log off an

Agency once it exhausts its daily cash limit or tries to perform unauthorized transaction. The pin and electronic transactions are encrypted and Submission of data to CBK every month among others.

\subsection{Empirical Review}

A banking agency is a retail or postal outlet contracted by a financial institution or a mobile network operator to process clients' transactions. Rather than a branch teller, it is the owner or an employee of the retail outlet who conducts the transaction and lets clients deposit, withdraw, and transfer funds, pay their bills, inquire about an account balance, or receive government benefits or a direct deposit from their employer. Banking agents can be pharmacies, supermarkets, convenience stores, lottery outlets, post offices, and many more. Mobile phones are proving to be a powerful tool for the delivery of basic financial services to lower income households throughout the world. In just a few years, millions of new mobile phone subscribers are now transferring money, sending international remittances and even saving through mobile phone networks. The term "mobile money" is used broadly to mean agency banking as most of transactions is carried out using mobile phone devices.

Globally, these retailers and post offices are increasingly utilized as important distribution channels for financial institutions. The points of service range from post offices in the Outback of Australia where clients from all banks can conduct their transactions, to rural France where the bank Credit Agricole uses corner stores to provide financial services, to small lottery outlets in Brazil at which clients can receive their social payments and access their bank accounts (AFI, 2010). Local regulation determines if financial institutions are allowed to work through retail outlets. Regulators generally determine what kind of, if any, financial institutions are permitted to contract banking agents, what products can be offered at the retail outlets, how financial institutions have to handle cash transport, Know Your Customer requirements, consumer protection, and other operational areas. There may also be an opportunity to quickly catalyze and capitalize a mobile money system. Agency banking has frequently benefited through a "push" by government. In these cases, the government works with commercial banks by reducing taxation on licenses, and regulations to encourage cheap products and services by banks through agents.

Most services in the categories are transaction-based. The non-transaction-based services of an informational nature are however essential for conducting transactions - for instance, balance inquiries might be needed before committing a money remittance. The accounting and brokerage services are therefore offered invariably in combination with information services. Information services, on the other hand, may be offered as an independent module. Mobile phone banking may also be used to help in business situations.

In developing markets, Agents are used to reach an "additional" client segment or geography. Banking Agents were formed in Brazil and in Colombia to help financial institutions to divert existing customers from crowded branches and to provide a "complementary", often more convenient channel. Also, low-income clients often feel more comfortable banking at their local store than walking into a marble branch. Brazil is a pioneer in Agency Banking. Since 1999, more than 100,000 retail outlets have been turned into Bank Agents, reaching 13 million extra unbanked people. Latin America banks, microfinance institutions, and mobile operators started to experiment with banking agency networks in various countries around the world such as Brazil, Peru, Colombia, Kenya, Mexico, Pakistan, the Philippines, and South Africa (AFL,2010)

The unbanked population in Kenya will be reached by banking agents in that they help the financial institutions to reach the unbanked customers cheaply without investing in branches providing a complementary 
often more convenient channel. Other financial institutions, especially in developing markets, use agents to reach an additional client segment or geography, reaching poor clients in rural areas is often prohibitively expensive for financial institutions since transaction numbers and volumes do not cover the cost of brick and mortal branch. In such environments banking agents use the existing retail infrastructure - and lower set up and running cost-can play a vital role in offering many low income people their first time access to a range of financial services. Also, low income clients feel more comfortable banking at their local store than walking into a From 2006 Colombia created non-banking correspondent whereby formal financial institutions allowed commercial businesses to provide financial services on their behalf. They performed every activity of the Bank except formally making the retail customer the client of the Bank. Mobile banking has offered the solution to this challenge. Mobile banking is the back bone of agency banking, performing banking over a mobile phone. It helps to convert cash into electronic money and vice versa by use of mobile phones; clients will have to visit a branch, automated teller machine (ATM), or banking agent. In the remote areas cash is the most used medium of exchange; therefore Agency Banking by use of mobile phones has changed the circumstance. The mobile regulation by CCK and mobile money by Central Bank are challenges but so far the two regulators have worked well to make Agency Banking a reality.

\subsection{Critique of existing Literature}

According to a survey on agency banking carried out by Kenya Bankers Association (KBA) for its Centre for Research on Financial Markets and Policy, 40.9\% of agents operations are cash deposits while 36\% are withdrawals. The survey also revealed that customers are asking for additional services not on offer, including ATM cards, recommendations for a loan given the closer interaction, loan processing and advice on various bank products on offer. While these would offer a distinction from services offered by Telco's' mobile money services, they require more expertise than agents have, and closer supervision than they can be given.

The survey also found that $91 \%$ of respondents will use an agency outlet because they trust the bank compared rather than the agent. Banks with positive images and long, stable operations are favored. Agents use point-of-sale (POS) devices and/or mobile phones and must have access to the bank's core banking system so that the clients' transactions are reflected in real time.

Dr. Anne Kamau, one of the researchers on the KBA survey, highlighted some of the pressing problems that have come up since the agency model inception: By its nature, the model was intended to take banking to the low income and rural populations. This places outlets in areas where insecurity is a concern. They lack the sophisticated security measures of the bank branch (CCTV, armed guards) and as the researchers observed, large deposits (large here means over KES50,000) were in some cases turned away. The outlets also operate beyond standard bank opening hours, further exacerbating the security risk. Other problems include: lack of consumer information on agency banking, for example on charges, lack of sufficient float, image problems (shabby shops may turn off customers); system collapse; equipment breakdown and incompetent agents.

\subsection{Research Gaps.}

In most cases the regulatory environment has focused on promoting the expansion of m-banking. Consumer protections are often lacking. Current research on the threats users face due to insufficient consumer protection regulation is lacking, as is any in-depth analysis of how to balance competing needs of the regulatory system. Rigorous, peer-reviewed studies on user issues are lacking. To date, most of the research on mobile banking has focused on supply-side issues. The evidence that does exist on the topic is anecdotal and does not provide conclusive evidence of user impacts, positive or negative.

Evidence of m-banking's benefits and risks is limited to studies on privileged populations, lacking knowledge about the portion of the population that stands to see the most gains from this technology.

Preliminary evidence suggests that travelling without cash in hand makes users feel safer, but there is little research on whether m-banking increases users' safety in practice. There has also been little research on the new security risks that m-banking users face, such as identity theft, fraud, and cyber theft.

\subsection{Introduction}

\section{Research Methodology}

This chapter presents a detailed methodology to be followed by the researcher to conduct the study. It includes the following sections; Location of the Study, Sample and Sampling Procedure, Research Instruments, Data Collection Procedure and Data Analysis Techniques. Research methodology refers to the methods that adhere to an orderly sequence of data Collection. It is a combination of various techniques used in collection of data for a Particular research to accomplish and realize its objectives. 


\subsection{Research Design}

A research design is the general plan of how one goes about answering the research questions Saunders, Lewis and Thorn hill, (2007). According to Cooper and Schlinder (2001), research design constitutes the blueprint for data collection, measurement and analysis. This study was carried out through a descriptive also known as survey design. This design was considered appropriate as it dealt with many members in a population where it was not possible to study all of them and hence calling for sampling in order to come up with a generalizations and inferences about the whole population.

\subsection{Population of the study and Sample size}

Population is defined as the total number of aggregate of all units possessing certain Characteristics from which a sample of study can be derived. The success of any research Depends on the extraction of the required information from the appropriate population. However, a research involving a large number of the population under study is sometimes impossible as it requires more resources in terms of time, finances and tools to collect data. A sample therefore needs to be drawn from the entire population that has sufficient Characteristics representing the population to draw accurate inferences from it.

The total population of Kenya Commercial Bank Mombasa County is two hundred employees, and out of this 39 are managers. The target population will involve all the 39 branch managers agency banking managers and agency banking consultants. This population was divided among seven branches in the Region all having the same characteristics required for the study.

The table below shows the total population in the organization, sample size and percentage of the targeted sample

Table 3. 1: Sample size

\begin{tabular}{|c|c|c|c|}
\hline BRANCH & $\begin{array}{ll}\text { NUMBER } & \text { OF } \\
\text { EMPLOYEES } & \\
\end{array}$ & SAMPLE SIZE & PERCENTAGE \\
\hline Kisauni & 19 & 5 & 2.5 \\
\hline Kengeleni & 19 & 4 & 2. \\
\hline Kilindini & 25 & 7 & 4 \\
\hline Mvita & 35 & 8 & 4 \\
\hline Mwembe Tayari & 19 & 4 & 2 \\
\hline Treasury Square & 50 & 8 & 4 \\
\hline Mombasa Court & 6 & 3 & 1.5 \\
\hline Total & 200 & 39 & 20 \\
\hline
\end{tabular}

\subsection{Sampling method}

A sample is a unit or portion of the target population with sufficient characteristics of the entire population. The key determinant of the sample size is the level of representation required; a high level of assurance can only be derived from a relatively large sample and vice-versa. The researcher used stratified random technique in selecting the sample size in which the respondents were arranged into strata that is according to Branches employee.

The sampling technique was chosen because it had a fair representation of the employees in the organization, where proper conclusion can be easily drawn from the research finding. The researchers choose a sample of $20 \%$ percent from the target population to ensure effective collection of data within the limited time and resources provided for the study.

\subsection{Data and Data Collection Techniques}

The researcher used a questionnaire for data collection. This is a data collection instrument which will entail a face to face dialogue consisting written questions constructed to provide information from respondents based on objectives of the study. The researcher used unstructured or open ended questionnaires that required the respondents to provide their own answers with no limit. The questionnaire was categorized in four different parts with each part covering the four variables of the study that is technology, regulation of agency related laws, lack of training and operational structure. The use of questionnaire is to provide more reliable data that ensures confidentiality and to cover the entire population in the shortest of time.

\subsection{Piloting}

According to Kothari (2004), validity indicates the degree to which an instrument measures what it is supposed to measure, that is the extent to which differences found with measuring instruments reflects true differences among those being tested to enhance validity of the study, a pilot study will be conducted on a population similar to the target population (Mulusa, 1998).The purpose is to assess the clarity and efficiency of the instrument items and take appropriate actions. Employees from a random KCB branch were randomly selected and involved in the pilot study to test the validity of research instruments. 


\subsection{Data Analysis Techniques}

Mugenda and Mugenda (2003) observe that the main purpose of content analysis is to study the existing information in order to determine factors that explain specific phenomena. Before data analysis data processing was done; this involved editing to detect any errors or emissions and data classification involved arranging data in common categories. All qualitative data was subjected to descriptive analysis using Microsoft excel tools. Descriptive statistics such as frequencies, percentages, bar charts and pie charts was used to systematically and meaningfully display the data for purpose of reporting. Data presentation was in form of frequency tables, pie charts, bar charts and percentages.

\subsection{Introduction}

\section{Research Findings And Analysis}

This chapter specifically presents the analysis and the results of the field data gathered from the agency banking Agents in Mombasa County. The purpose of this study was to establish the challenges facing the implementation of agency banking in Kenya Commercial Bank Mombasa County. Among the factors investigated included: technological factors, regulation of agency related laws, operational structure and low level of training. The study gathered responses from a total of 30 bank personnel within Mombasa County. These formed the basis of the findings presented in this chapter. Among the data analysis techniques adopted included; descriptive statistics method such as frequencies and percentages were used. The findings were presented in form of frequency distribution tables, percentages, pie charts and bar graphs.

Preliminary analysis procedures of cleaning, frequencies, consistency checks, and debugging were done on the data obtained. This further improved the quality of the data collected. Only $30 / 39$ questionnaires given out were returned, thus forming a response rate of $84.5 \%$.The next section shows the results.

\subsection{Response rate}

The researcher distributed 39 questionnaires to the respondents and received 30 of them back. This therefore indicates that the response is reliable since more than $50 \%$ of feedback was received. This is shown in the table 4.1 below.

Table 4. 1: Response rate

\begin{tabular}{llll}
\hline Category & Target population & Response rate & Response percentage \\
\hline Kisauni & 5 & 3 & 7.7 \\
Kengeleni & 4 & 3 & 7.7 \\
Kilindini & 7 & 7 & 17.9 \\
Mvita & 8 & 6 & 15.4 \\
Mwembe Tayari & 4 & 4 & 10.2 \\
Treasury Square & 8 & 7 & 17.9 \\
Mombasa Court & 3 & 3 & 7.7 \\
\hline TOTAL & $\mathbf{3 9}$ & $\mathbf{3 0}$ & $\mathbf{8 4 . 5 \%}$ \\
\hline
\end{tabular}

\subsection{Branch's years of operation since establishment}

The respondents were asked to indicate how many years their respective branches have been in operation. The results are shown in Table 4.1

Table 4. 2 Branch's years of operation since establishment

\begin{tabular}{lll}
\hline Number of years & Frequency & Percentage \\
\hline $0-10$ years & 3 & 10 \\
11-20 years & 7 & 23 \\
21-30 years & 8 & 27 \\
Above 30 years & 12 & 40 \\
\hline Total & $\mathbf{3 0}$ & $\mathbf{1 0 0 \%}$ \\
\hline
\end{tabular}

As shown in Table 4.1, 67\% of the respondent branches have been in operation for over 20 years, and $33 \%$ for less than 20 years, with only $10 \%$ having been set up in the last 10 years. This could imply a slow growth in the number of players possibly due to high barriers to entry.

\subsection{Respondents' Profiles}

This section shows the demographic details of the respondents. The respondents were asked to indicate their position in the bank. The results are shown in Figure 4.2 and table 4.2 respectively. 


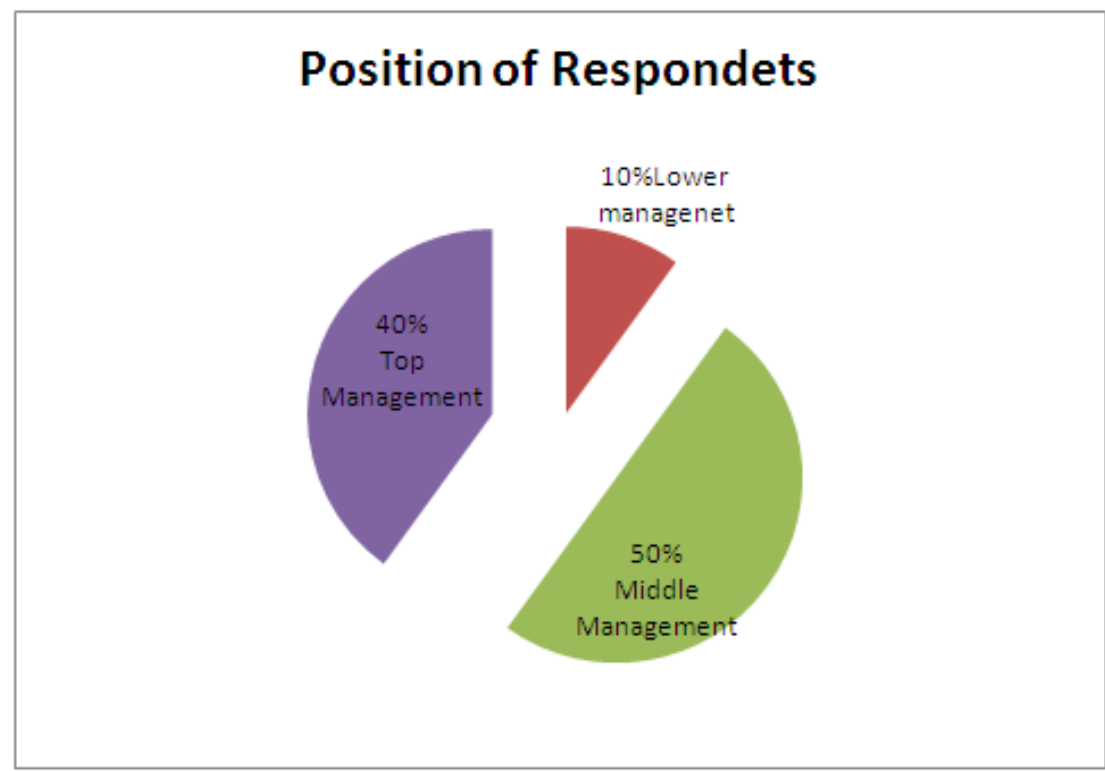

Figure 4.1 Positions held in the bank by Respondents

As shown in figure 4.2 above $40 \%$ of the respondents were in top management positions, $50 \%$ in middle management, and only $10 \%$ in lower management. This portrays the fact that agency banking had not yet been operationalized and that the necessary operational framework and infrastructure were yet to be fully being established.

Table 4. 3 Positions of Respondents

\begin{tabular}{lll}
\hline Position & Frequency & Percentage \\
\hline Top management & 12 & 40 \\
Middle management & 15 & 50 \\
Lower management & 3 & 10 \\
\hline Total & 30 & 100 \\
\hline
\end{tabular}

Table 4.2 above further illustrates that 27 out of the 30 respondents are in top and middle level of management while on 3 are in lower management, this indicates that the top and middle level managers have a lot of influence on policy and decision making on several factors due to their numerical strength.

4.5 Demographic distribution of respondents' years of service at KCB

The respondents were asked to indicate their length of service in the bank. The results are as shown in Table 4.3 below

Table 4.4: Demographic Information about the Sample-Duration of having worked in KCB

\begin{tabular}{llll} 
Total & & $\mathbf{3 0}$ & $\mathbf{1 0 0 \%}$ \\
\hline Factors & Category & Frequency & $\mathbf{\%}$ \\
\hline Duration of working in the organization & Less than 3 years & 5 & 17 \\
& 3-5 years & 13 & 43 \\
& 5-10 years & 10 & 33 \\
& Above 10 years & 2 & 7 \\
\hline
\end{tabular}

Table 4.3 indicates that $17 \%$ of the respondents had worked in the institution for less than 3 years, $43 \%$ for a period of 3-5 years, and 33\% for 5-10 years while 7\% for more than 10 years. Therefore a majority of the staff at $73 \%$ have worked for the bank for at least 5 years. These employees must have joined the bank in the initial stages of agency banking introduction in the market thus they are fully aware or have a clue what agency banking entails. Figure 4.3 below further illustrates the researcher's findings. 


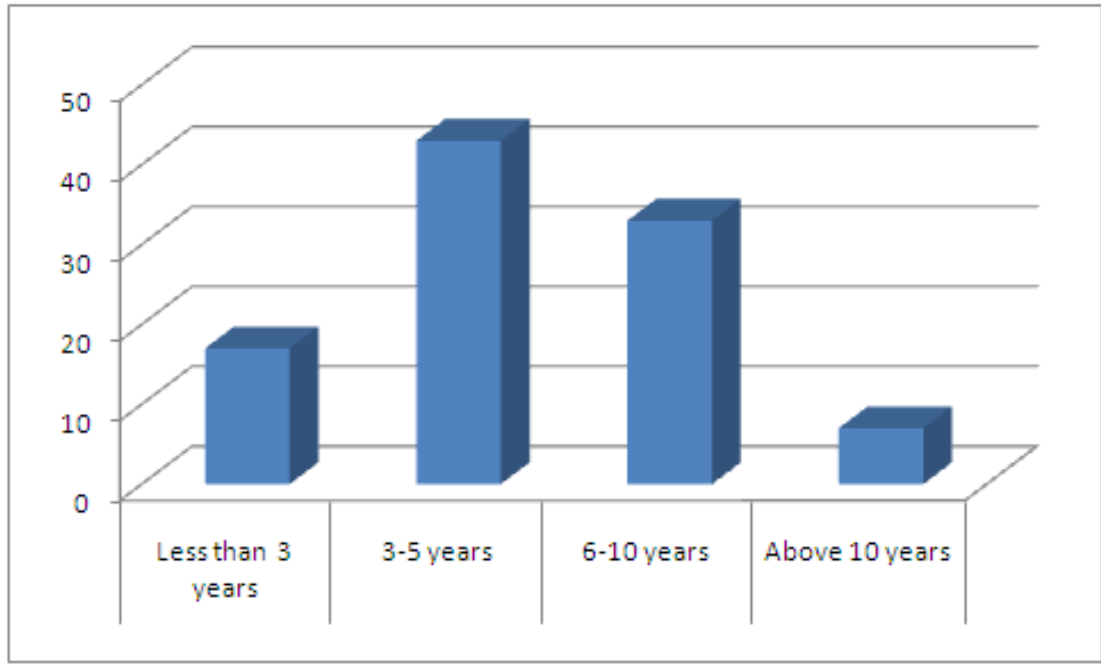

Figure 4.2 Demographic distribution of the sample (Duration of working at KCB)

According to the findings Figure 4.3 further illustrates from data collected indicates that 23 out of the 30 respondents have worked for the bank for at least 5 years. The respondents were asked to indicate the length of service in their current positions and the findings are summarized in table 4.4 below

Table 4.5 Demographic information on sample length of service in their current positions

According to the findings $86 \%$ of the respondents had served in their current positions for less than 5 years, which may imply job rotation, upward career mobility, and the creation of posts arising from the introduction of agency banking.

\begin{tabular}{llll}
\hline Factors & Category & Frequency & $\mathbf{\%}$ \\
\hline Duration of working in current position & Less than 3 years & 14 & 46 \\
& 3-5 years & 12 & 40 \\
& 6-10 years & 4 & 14 \\
& Above 10 years & 0 & 0 \\
\hline Total & & 30 & $100 \%$ \\
\hline
\end{tabular}

\subsection{Banks' Likelihood of Agency Banking Implementation}

The respondents were asked to state to what extent their respective banks consider adopting agency banking. The results are shown in Table 4.5 below

Table 4.6 Respondents perception of Banks’ Likelihood to implement Agency banking

\begin{tabular}{lll}
\hline Factors & Frequency & $\mathbf{\%}$ \\
\hline Not applicable & 3 & 10 \\
To a limited extent & 0 & 0 \\
To a moderate extent & 9 & 30 \\
To a great extent & 9 & 30 \\
To a very great extent & 9 & 30 \\
\hline Total & $\mathbf{3 0}$ & $\mathbf{1 0 0 \%}$ \\
\hline
\end{tabular}

The study sought to establish the degree to which agency banking is applicable and from findings given in table 4.5 above $10 \%$ of the respondents think that agency banking is "Not applicable" these are branches that are yet to recruit agents or have one or two three agents who are not very active in the market.30\% of the respondents are of the view that agency banking is applicable to moderate extent, this is attributed to the fact that those respective branches have put in the place the infrastructure to implement agency banking but are yet to operationalise agency banking. However none of the respondents is of the view that agency banking can be implemented to a limited extent $.30 \%$ of the respondents believe that agency banking can be implemented "to a great extent "these are branches that are considering recruiting a large number of agents. $30 \%$ of the respondents believe that agency banking can be implemented "to a very great extent" represents. Branches that have hit the road running and have recruited a lot of agents and have invested in the infrastructure to enable operations to run smoothly already embarked on recruitment of agents. As shown in Table 4.5, 30\% for moderate, great and very great likelihood of agency banking implementation respectively indicates a high inclination towards the implementation of agency banking by most respondent branches. 
The Challenges Facing the Implementation of Agency Banking In Kenya a Case Study of Kcb ....

\subsection{Effect of Operational structure on Agency Banking Implementation}

Strategy used by an organization is fundamentally influenced by the operational structure of the organization. It dictates how policies and objectives are established and how resources are allocated. When an organization changes its strategy, the existing organization structure may be ineffective. Agency banking being a new concept has forced banks to realign or change some of its structures so as to accommodate agency banking, thus this study sought to find out how operational structure affects implementation of agency banking in KCB Mombasa County. Table 4.6 below shows the extent to which the respondents agree or disagree with some of the factors

Table 4.7 Extent to which Operational Structure Affect Agency banking implementation

\begin{tabular}{|c|c|c|c|c|c|}
\hline Factor & $\begin{array}{l}\text { Strongly } \\
\text { Disagree }\end{array}$ & Disagree & Neutral & Agree & $\begin{array}{l}\text { Strongly } \\
\text { Agree }\end{array}$ \\
\hline $\begin{array}{l}\text { Agency banking is easy to understand and use } \\
\text { Collaboration with other banks on various } \\
\text { aspects e.g. receiving agents deposits on behalf }\end{array}$ & 5 & 10 & 10 & 35 & 40 \\
\hline $\begin{array}{l}\text { of other banks, has an impact on implementation of } \mathrm{AB} \text { services. } \\
\text { Managing credit risk, operational risk, liquidity } \\
\text { risk and reputation risk greatly influences } \mathrm{AB}\end{array}$ & $\mathbf{0}$ & 10 & 20 & 40 & 30 \\
\hline Implementation. & $\mathbf{0}$ & $\mathbf{0}$ & 10 & 50 & 40 \\
\hline & $\mathbf{0}$ & $\mathbf{0}$ & $\mathbf{0}$ & 60 & 40 \\
\hline & 55 & 30 & 4 & 6 & $\mathbf{0}$ \\
\hline $\begin{array}{l}\text { Information sharing on the various channels of communication has an } \\
\text { impact on implementation } \\
\text { of } \mathrm{AB} \text { services }\end{array}$ & $\mathbf{0}$ & $\mathbf{0}$ & 5 & 45 & 50 \\
\hline
\end{tabular}

Table 4.6 indicates that $75 \%$ of the respondents believe that agency banking is easy to use and understand while $70 \%$ believe that Collaboration with other banks on various aspects e.g. receiving agents deposits on behalf of other banks, has an impact on implementation of AB services. $90 \%$ are of the opinion that managing credit risk, operational risk, liquidity risk and reputation risk greatly influences $\mathrm{AB}$ and $100 \%$ of the respondents believe that resources allocation has an impact on implementation of $\mathrm{AB}$ services. $85 \%$ of the respondents do not believe that their interaction with agency banking primary relates to potential misuse of or unauthorized access to users sensitive information, $95 \%$ of the respondents believe information sharing on the various channels of communication has an impact on implementation of agency banking services

\subsection{Effect of Technological Factors on Agency Banking Implementation}

Technology involves application of knowledge, tools and skills to solve problems and extend human capacity (Mberia, 2009). Agency banking is a modern technology which uses recently invented gadgets such as mobile phones to operate, however technological changes and innovations have become so rapid that most organizations are playing catch up and since agency banking heavily relies on the technology platform to operate this study sought to establish how technological risks affect agency banking implementation. Respondents were asked the extent to which they agree or disagreed with some of those factors and the results are summarized in table 4.7 below.

Table 4.8 Extent to which Technological Factors Affect Agency Banking Implementation

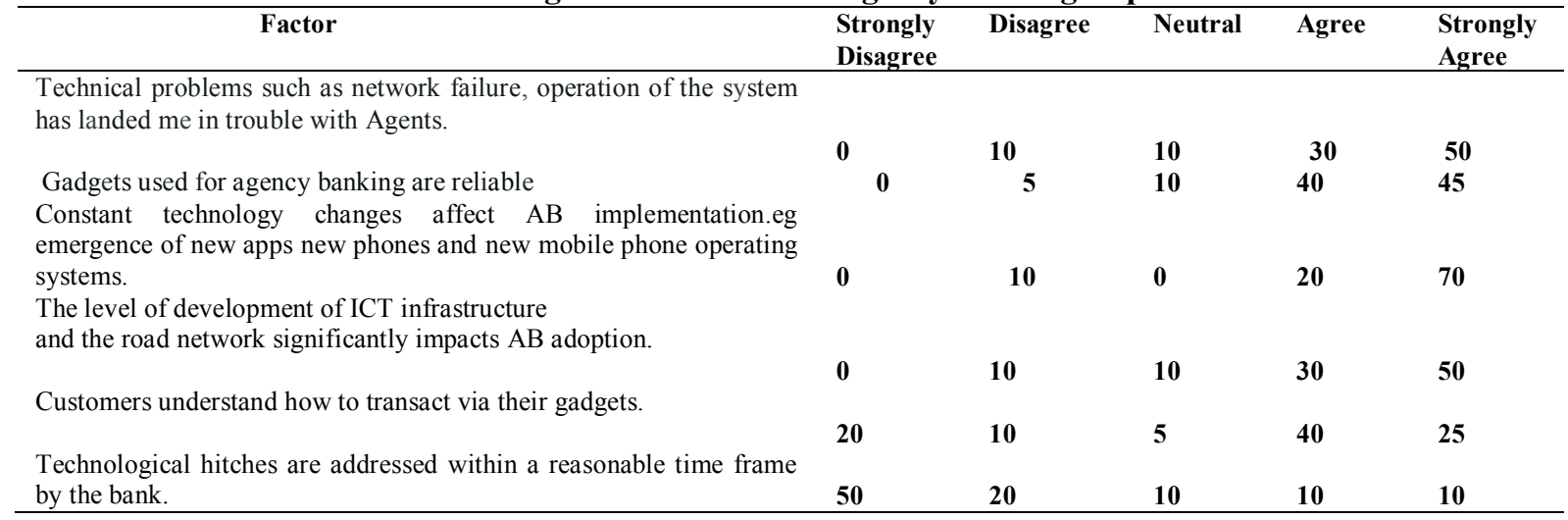

From the findings in table $4.780 \%$ of the respondents are of the opinion that technical problems such as network failure, operation of the system has landed them in trouble with Agents while $10 \%$ have a neutral 
response and the other $10 \%$ do not agree that technical problems such as network failure, operation of the system has landed them in trouble with Agents, $85 \%$ of the respondents believe that the gadgets used for agency banking are reliable $5 \%$ disagree and $10 \%$ are of a neutral position, $90 \%$ strongly agree that constant technology changes affect $\mathrm{AB}$ implementation.eg emergence of new apps new phones and new mobile phone operating systems and $10 \%$ disagree. The data on the level of development of ICT infrastructure and the road network significantly impacts $\mathrm{AB}$ implementation $80 \%$ believe agree that it indeed impacts on implementation of agency banking $10 \%$ disagree and $10 \%$ are neutral. $65 \%$ agree that customers understand how to transact via their gadgets,20\&strongly disagree with the statement, $10 \%$ disagree while $5 \%$ are neutral. $70 \%$ of the respondents disagree that technological hitches are addressed within a reasonable time frame by the bank while $20 \%$ agree that technological hitches are addressed within a reasonable time frame, however $10 \%$ took a neutral stand.

\subsection{Effects of Regulation of Agency related laws on agency banking implementation}

There are a number of state set legislative and regulatory Acts that regulates the agency banking industry. This study sought to establish whether the respondents were conversant with the contents of the various set legislative Acts that control agency banking thus the study sought to find out if the respondents understood the regulations by CBK and the results are shown in figure 4.4 below

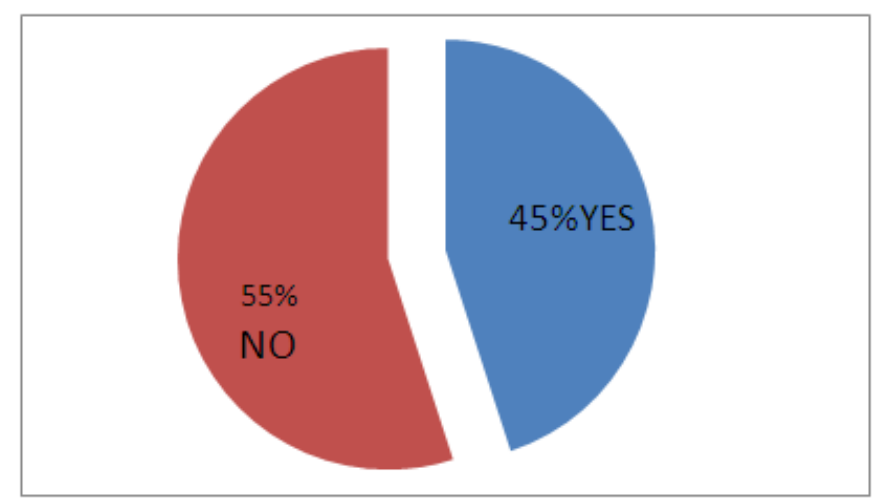

Figure 4.3 If respondents understand Agency banking regulations by CBK

From the findings, $55 \%$ of the respondents indicated that they didn't understand agency banking regulations by CBK while $45 \%$ of the respondents indicated that they understood agency banking regulations by CBK. This therefore implies that some regulations are being flouted or some disregarded entirely.

Further the views of the respondents were sought with regard as to whether or not the vetting procedure and due diligence is tedious and their response were as contained in figure 4.5 below.

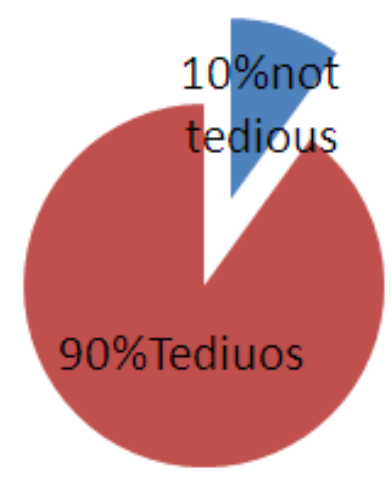

Figure 4.4 Pie chart showing respondents perception on vetting procedure and due diligence.

From the findings, $90 \%$ of the respondents indicated that the vetting procedure and due diligence was tedious while $10 \%$ of the respondents indicated that the vetting procedure, due diligence wasn't tedious which indicates that the turnaround time to set up agents and get them running is not business friendly thus it does not create the environment that would shorten or even encourage agency banking implementation. Thus the respondents were asked to give their views on the duration of document witnessing by lawyers and bank and their response were as in table 4.6 below 


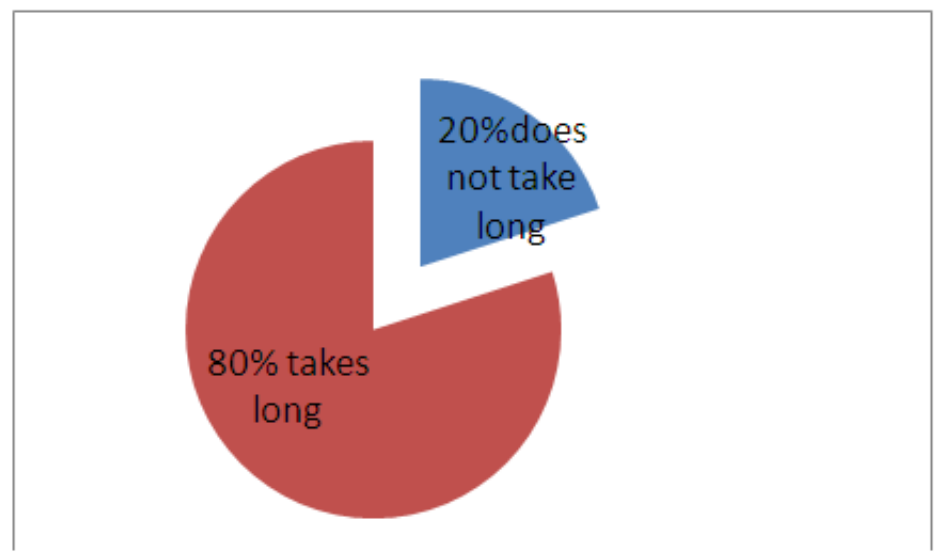

Figure 4.5 Respondents perception on duration of document witnessing by lawyers and bank

According to the findings, $80 \%$ of the respondents indicated that the document witnessing by the lawyers and bank took long while $20 \%$ of the respondents indicated that the document witnessing by the lawyers and bank didn't take long. This also hinders implementation of agency banking in that the time frame for documentation is too long thus taking a toll on completion of paperwork.

On whether or not the respondents were conversant with the State Legislations the response collected were as in figure 4.7 below

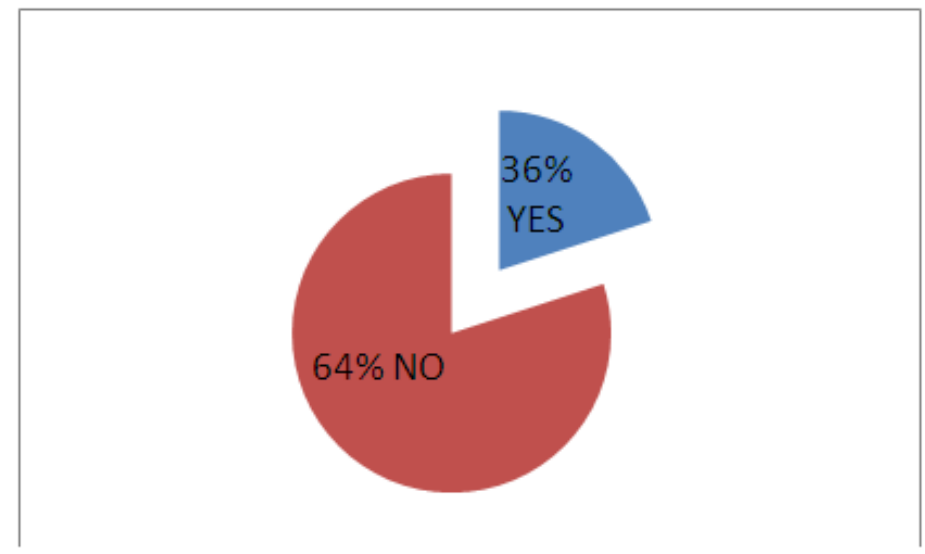

Figure 4.6 Whether respondents are Conversant with the State Legislations

From the findings, $64 \%$ of the respondents indicated that they were not conversant with the state legislations while $36 \%$ of the respondents indicated that they were conversant with the state legislations. The respondents were asked if government regulatory issues affected their business and the responses are shown in figure 4.8 below

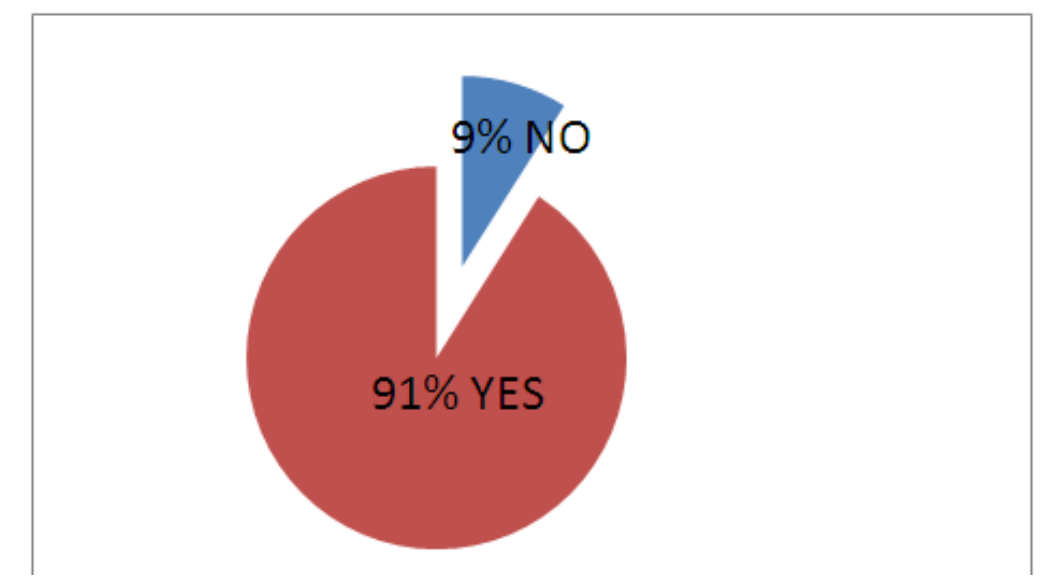

Figure 4.7 If respondents Business is affected by Government Regulatory Issue 
According to the findings, $91 \%$ of the respondents indicated that their business was affected by Government regulatory issues while $9 \%$ of the respondents indicated that their businesses were not affected by Government regulatory issue.

\subsection{0: Effects of lack of Training on AgencyBanking Implementation}

The last objective of this study was to determine how lack of training affects implementation of agency banking and the respondents were asked if they had received any training from the bank and the findings are summarized in figure 4.9 below

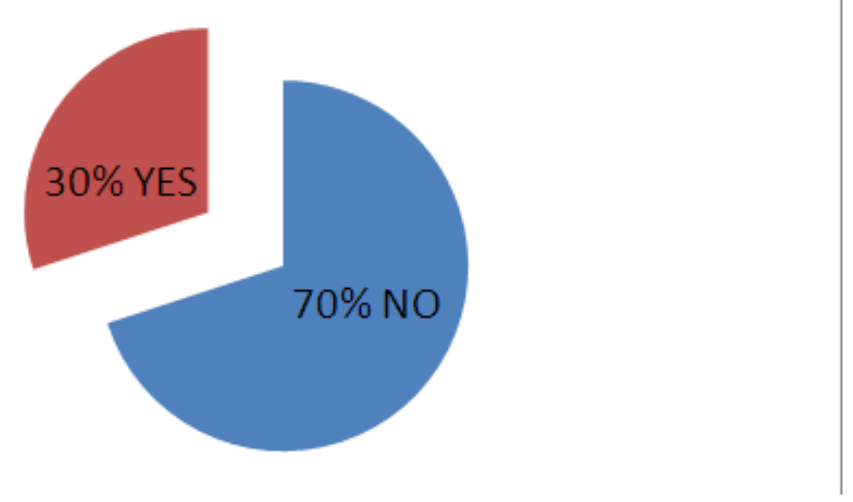

Figure 4.8 if respondents have received any training from the bank

According to the findings, $30 \%$ of the respondents indicated that they have received training from the bank on agency banking while $70 \%$ of the respondents indicated that they have not received any training from the bank. The study then sought to find out from the respondents whether they would like to be trained by the bank and their responses were as in figure 4.10 below

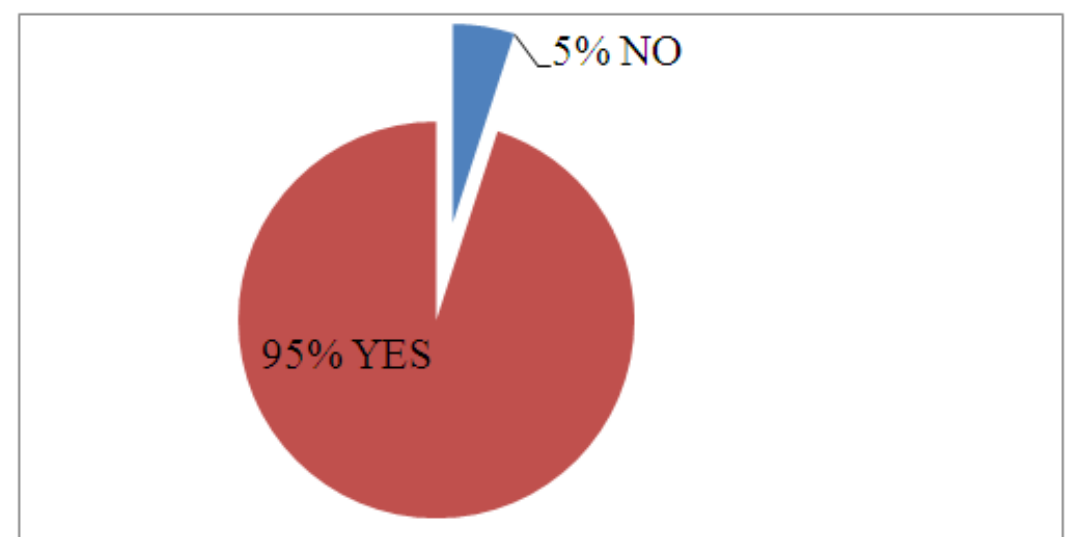

Figure 4.9 if respondents would like to be trained on agency banking

According to the findings, $95 \%$ of the respondents indicated that they would have liked to be trained on agency banking while $5 \%$ of the respondents indicated that they were not willing to be trained on agency banking. This shows that the respondents have a positive projection towards agency banking.

\subsection{Introduction}

\section{Summary, Conclusions And Recommendations}

This chapter presents summary of the study in conjunction with findings as presented in previous chapter. It also provides the conclusion and recommendations for further research on the items under study.

\subsection{Summary of the findings.}

\subsubsection{Regulation of Agency related laws}

The study found out that $55 \%$ of the respondents did not understand agency banking regulations by CBK, $90 \%$ are of the opinion that the vetting procedure, due diligence was tedious, $80 \%$ confirmed that document witnessing by the lawyers and bank took long, that $64 \%$ were not conversant with the state 
legislations thus it means that a majority of the respondents are not in tandem with any of the agency regulation policies by the CBK show how the banks personnel are not in touch with what should be their guide and blue print towards agency banking implementation.

\subsubsection{Technology based factors}

The majority of the respondents indicated that technical problems such as network failure and operation of the system had landed them in problems with agents, constant technology changes, extended times frames to address technological hitches and unreliability of existing telecommunication, low level of development of ICT infrastructure and the road network negatively inhibited them from carrying out their functions thus based on these findings it was concluded that the implementation of agency banking was significantly affected by technological factors thus banks ought come up with strategies that to address the above concerns.

\subsubsection{Lack of training}

According to the findings of this study $70 \%$ of the respondents had not received any training from the bank on agency banking while $95 \%$ were willing to be trained on agency banking thus indicating that the bank personnel have embraced the concept of agency banking and that implementation of the same is hindered by a lack of knowhow which is as a result of total lack of training.

\subsubsection{Operational Structure}

From the study finding, the researcher noted that for a strategy to be successful in its implementation, the allocation of resources and Information sharing on the various channels of communication is very vital, Respondents strongly agreed and these two factors had percentages of $100 \%$ and $95 \%$ respectively. The study further revealed that Collaboration with other banks on various aspects e.g. receiving agents' deposits on behalf of other banks and Managing credit risk, operational risk, liquidity risk and reputation risk greatly influences AB Implementation with $70 \%$ of the respondents agreeing with that particular factor.

\subsection{Conclusion}

The findings of the study reveal that the banking sector is eager to embrace agency banking as an alternative service delivery channel. Agency banking presents opportunity for rapid expansion at minimal cost by leveraging on the existing investment of the retail agents through information and communication technology. The study shows that the main challenges facing agency banking implementation among KCB branches in Mombasa County are poor resource allocation, outdated and ineffective technological instruments and lack of training of staff on the relevant policy issues and factors that have a bearing on agency banking.

\subsection{Recommendations}

The bank should adequately train its staff in preparation for implementation of any strategy to be successful. The training should ensure all employees understand the strategy, its goals and objectives and their expected contribution to its successful implementation. For any strategy to be successfully implemented, the management needs to be supportive and ensure that all the resources required are available.

The researcher further recommends that, the regulator closely monitors the banking sector and strictly enforces compliance with the agency banking guidelines, while the banks continuously ensure careful vetting of agents documents.

Technology should be the main link between the bank and its agents. The bank needs to update its technology that links Point of Sale and the main banking system and address the various technological hitches experienced in its network to ensure smooth operation and delivery of agency banking services.

\section{Acknowledgement}

I thank the Almighty God for giving me the energy and wisdom to do this project. I am grateful to my supervisor Dr.Kerongo for guidance, suggestions, corrections and critique to this work.

\section{References}

[1]. Ali, M. A. (2008). Strategic issue management practices by commercial banks in Kenya. Unpublished MBA project, University of Nairobi.

[2]. Ankem, K. (2004). Adoption of Internet resource-based value-added processes. Library Information Science Research, 26(4), $482-500$.

[3]. Byers, R.E. and Lederer, P.L. (2001) 'Retail banking service strategy: a model of traditional electronic, and mixed distribution choices', Journal of Management Information Systems, Vol. 18, No. 2, pp.133-156. Retrieved from http://www.scribd.com/doc/46473396/Ahmed-E-Banking-Paper-09

[4]. Carayannis, E., Alexander, J., \& Mason, W. (2006).Technology management. Encyclopedia of Management. Ed. Marilyn Helms, D.B.A. 5th ed. Detroit: pp 892-899. Retrieved from http://www.ariadne.ac.uk/issue50/oppenheim-et-al/

[5]. Central Bank of Kenya. (2009). Central Bank of Kenya Annual Report. 
[6]. Central Bank of Kenya. (2010). Central Bank of Kenya Annual Report

[7]. Central Bank of Kenya. (2009). Report on the knowledge on agencybanking to Brazil and Columbia.

[8]. Claessens S. (2006). "Access to Financial Services: A Review of the Issues and Public Policy Objectives," The World Bank Research Observer (21:2), pp. 207-240.

[9]. Daniel, E. (1999). Provision of Electronic Banking in the UK and the Republic of Ireland. The international Journal of Bank Marketing, Vol 17.

[10]. Denning, P. (2004). Building a culture of innovation F (8) Retrieved from http://www/acm.org/ubiquity/interviews/ Helms, (2006). Access for All. Washington DC: World Bank Publications.

[11]. Hernandez-Coss, R. (2009). Banking Agents in Mexico: Promoting access to finance

[12]. Ivatury, G. (2006). "Using Technology to Build Inclusive Financial Systems." CGAP

[13]. Ivatury, G., Mas, I.(2008). The early experience with branchless banking. CGAP Focus

[14]. Kibera, F., Waruingi, B.C. (1998). Fundamentals of marketing: An African perspective.

[15]. Kinuthia, M. N., (2008). Influence of credit cards on the growth of retail banking Project, University of Nairobi.

[16]. Kisia, B. A. (2006). An analysis of factors affecting the provision of services by banks to National Bank of Kenya Ltd., Unpublished MBA project, University of Nairobi.

[17]. Kisungu, N. (2007). An empirical study of the relationship between managerial skill and banks in Kenya. Unpublished MBA project, University of Nairobi.

[18]. Kotler, P. (2003). Marketing Management. 11th Edition, Prentice Hall, New Jersey Kumar, A., Nair, A., Parsons, A., \& Urdapilleta, E. (2006). "Expanding Bank Outreach through Retail Partnerships: Correspondent Banking in Brazil," World Bank Working Paper no. 85, Washington DC.

[19]. Ledgerwood, J., \& White, V. (2006). Transforming Microfinance Institutions Providing World Bank, Washington D.C. [20]. Lyman T, Ivatury G and Staschen S. (2006). Use of agents in branchless banking for the poor: rewards, risks and regulations. CGAP Focus Note No. 38, Washington D.C.

[21]. Mann, P.S. (1995). Introductory statistics, 2nd Edition, Wiley Mas, I, (2008). Realizing the Potential of Branchless Banking: Challenges ahead.

[22]. Mas, I., Siediek, H.(2008). Banking through Networks of Retail Agents. CGAP Focus

[23]. Mberia, P M. (2009). Factors affecting the operations of m-payment agents in Kenya.

Asian Development Bank.

Focus Note No. 3: Washingon, D.C.

Note No. 46, Washington, D.C.

Nairobi, Kenya

business in Kenya. Unpublished MBA

international business: A case of

technical efficiency of commercial

Full Financial Services to the Poor, Note No. 47, Washingon, D.C.

[24]. Unpublished master's thesis Kenyatta University, Nairobi Kenya.

[25]. Mitchell, A. (1995). Distribution Revolution (Part one): Changing Channels.

[26]. Otunya, P. (2006). A survey of consumer adoption of mobile phone banking in Kenya, Unpublished MBA project, University of Nairobi.

[27]. Perry, R. (2006). Diffusion theories. Encyclopedia of Sociology. Eds. Edgar F. Borgatta 2nd ed. New York: Macmillan Reference USA, 2001.674-681.

[28]. Rhyne E. (2007). The next banking revolution commentary: Microfinance is not just http://www.accion.org/Page.aspx?pid=1749

[29]. Rogers, E.M. (2003). Diffusion of Innovations, 5th Edition, New York: 38 Free Press.

[30]. State Bank of Pakistan. (2007) Branchless Banking Guidelines for financial institutions banking.

[31]. Steadman Group. (2007). Understanding Kenya's Financial Landscape. Financial Access in Kenya Survey: Nairobi, Kenya.

[32]. Stegman, A., Rocha, M. \& Davis, W. (2005) The Role of Technology in Serving the Unbanked The Frank Hawkins Kenan Institute of Private Enterprise, University of North Carolina.

[33]. UNDP. (2007). The United Nations Development Programme Annual Report.

[34]. Wejnert, B. (2002). Integrating Models of Diffusion of Innovations: A conceptual Framework. Annual Review of Sociology (Annual Reviews) 28: 297-306

[35]. World Bank. (2006). Africa Region: Making Finance Work for Africa. World Bank Publications: Washington DC.

\section{Appendix I: Introduction letter \\ Introduction}

Dear Respondent

I am a Student at Jomo Kenyatta University of Agriculture and Technology pursuing a Masters Degree in Business Administration (Markerting). I am an employee of KCB- Kenya Commercial Bank Kengeleni Branch and am carrying out a Research study on the challenges facing agencybanking implementation in your branch.

\section{Confidentiality and Consent}

I humbly request for your assistance in filling this questionnaire. Some of the questions may be very personal but you are assured of total confidentiality since any information given will be strictly handled and kept confidential as it will be used for the academic purposes.

Your contribution in answering the questionnaire will be highly appreciated.

Thanking you in advance for your cooperation,

Yours faithfully,

Titus Agalla

\section{Appendix II: Questionnaire}

Part A: General Information.

1. What is the name of your branch

2. How many branches does your bank have in Mombasa? 
3. How old is your branch?

$0-10$ Years ()

$11-20$ Years ()

$21-30$ Years ( )

Above 30 years ()

4. How many employees does your branch have?

5 . What is your position in the bank?

Top management ( )

Middle management ( )

Lower management ( )

6. How long have you worked in Kenya Commercial Bank? (Tick as appropriate)

\begin{tabular}{|l|l|l|l|l|}
\hline Length & Below 3 Years & $3-5$ years & $5-10$ years & Above 10 years \\
\hline Response & & & & \\
\hline
\end{tabular}

7. How long have you worked in the current position?

8. To what extent do you consider implementation of agency banking?

Not applicable ( )

To a limited extent ( )

To a moderate extent ( )

To a great extent ()

To a very great extent ( )

9. Kindly state the main factors that affect the implementation of agencybanking.

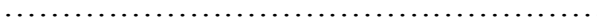

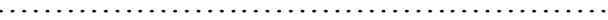

Part B: Operational Structure

10. Kindly indicate the extent to which you agree with each of the following statements as regards the adoption of agencybanking by your branch.

\begin{tabular}{|c|c|c|c|c|c|}
\hline \multirow[t]{2}{*}{ Factor } & $\begin{array}{l}\text { Strongly } \\
\text { Disagree }\end{array}$ & Disagree & Neutral & Agree & $\begin{array}{l}\text { Strongly } \\
\text { Agree }\end{array}$ \\
\hline & 1 & 2 & 3 & 4 & 5 \\
\hline \multicolumn{6}{|l|}{ Agencybanking is easy to understand and use } \\
\hline \multicolumn{6}{|l|}{$\begin{array}{l}\text { Collaboration with other banks on various } \\
\text { aspects e.g. receiving agents deposits on behalf } \\
\text { of other banks, has an impact on implementation of } \mathrm{AB} \text { services }\end{array}$} \\
\hline \multicolumn{6}{|l|}{$\begin{array}{l}\text { Managing credit risk, operational risk, liquidity } \\
\text { risk and reputation risk greatly influences } \mathrm{AB} \\
\text { Adoption. }\end{array}$} \\
\hline \multicolumn{6}{|l|}{ Resources allocation has an impact on implementation of $\mathrm{AB}$ services } \\
\hline \multicolumn{6}{|l|}{$\begin{array}{l}\text { My interaction with agencybanking primary relates to potential } \\
\text { misuse of or unauthorized access to users sensitive information }\end{array}$} \\
\hline $\begin{array}{l}\text { Information sharing on the various channels of communication has an } \\
\text { impact on implementation } \\
\text { of AB services }\end{array}$ & & & & & \\
\hline
\end{tabular}

PART C: Technological Factors

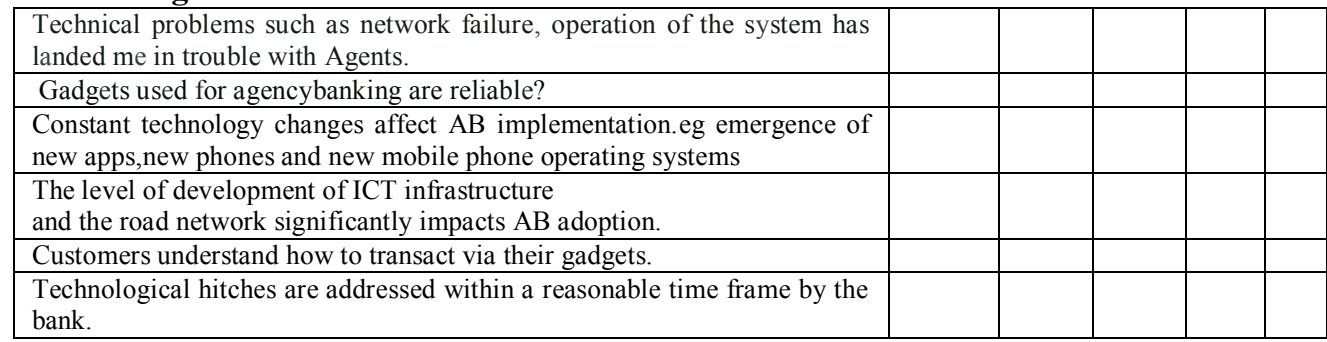

PART D: Regulation of Agencyrelated laws

1. Do your agents understand agencybanking regulations by CBK?

a) Yes 
b) No

2. Is the vetting procedure, due diligence tedious?

c) Yes

d) No

3. Does the document witnessing by the lawyers and bank take long?

e) Yes

f) No

4. Are you conversant with the state legislations?

g) Yes

h) No

5. If yes above, which acts are you conversant with?

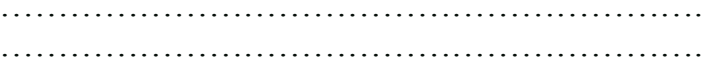

6. Is your business affected by Government regulatory policies?

a) Yes ...............

b) $\mathrm{No}$

\section{PART E: Low level of training}

7. Have you received any training from the bank?

g) Yes.

h) No.

8. Would you like to be trained on agencybanking?

c) Yes.

d) No.

10. Kindly give any other comments you may have about agencybanking

$\overline{\text { Your participation and }}$ assistance is highly appreciated!

Appendix III: Proposed Research Budget
\begin{tabular}{|l|ll|}
\hline PARTICULARS & COST(KSHS) \\
\hline Stationary & 7000 & \\
Transport & 3000 & \\
Publishing & & 16000 \\
Printing & 5000 & \\
Photocopy & 1500 & \\
Binding & 7000 & \\
Support services & 3000 \\
\hline Total & $\mathbf{4 2 5 0 0}$ \\
\hline
\end{tabular}

Appendix IV: Proposed Research Time Plan

\begin{tabular}{|l|l|l|l|l|l|l|l|}
\hline ACTIVITY & JUNE 2014 & JULY 2014 & AUG 2014 & SEP 2014 & OCT 2014 & NOV 2014 & DEC 2014 \\
\hline Proposal writing & & & & & & & \\
\hline Proposal presentation & & & & & & & \\
\hline $\begin{array}{l}\text { Corrections and } \\
\text { amendments }\end{array}$ & & & & & & & \\
\hline Data Collection & & & & & & & \\
\hline Data analysis & & & & & & & \\
\hline Report writing & & & & & & & \\
\hline Graduation & & & & & & & \\
\hline
\end{tabular}

